\title{
FORMS OF HAND IN SIGN LANGUAGE IN BOSNIA AND HERZEGOVINA - PRACTICAL EXAMPLES
}

\section{Esad H. Mahmutović ${ }^{1}$ Husnija Hasanbegović}

Center for Education and Rehabilitation of hearing and speech, Tuzla Faculty of Education and Rehabilitation, University of Tuzla

\author{
Original scientific paper
}

UDC: $81,221.24(497.6)$

Received: 08.06.2014.

Accepted: 11.08.2014.

\begin{abstract}
In this work there is shown illustration of 14 newly discovered forms of hand in sign language (SL) in B\&H, and one photographic presentation for each of the signs in which that form of the hand is represented. The goal of this work was to visualize the newly discovered forms of hand in order to ensure their adequate practical application in everyday communication of the deaf, various studies of sign language and future scientific analysis. Considering that the analysis of the contents in study is encompassing only 425 signs SL in B\&H, it can be concluded that future linguistic research, among other results in the purpose of its standardization, could discover new forms of hand.
\end{abstract}

Key words: Sign Language in B\&H, forms of hand, sign.

\section{INTRODUCTION}

The studies of sign language, although small in number, have contributed significantly to its affirmation. These studies dealt with the importance of hand alphabet (Hasanbegovic, 2004; Kasumovic and Hasanbegovic, 2005), difficulties and problems in communication of hard of hearing children with their parents (Kurtagic, 2005), the advantages of hand alphabet (Finger Font) for the deaf over the latin alphabet (Hasanbegovic, 2006; 2012), the status of SL in B\&H and the position of the deaf people in $\mathrm{B} \& \mathrm{H}$ in relation to the communication mode (master thesis Mahmutovic and Salkic, 2008).

Besides the research on affirmation of the SL in $\mathrm{B} \& \mathrm{H}$, significant for its practical application is the publication of Dictionary for the deaf (Kasumovic and Hasanbegovic, 2002), dictionary "Do you speak sign?" (SUGOSG B\&H, 2005; 2007) and Bilingual glossary (Hasanbegovic, 2011), and the particularly important is the research of the form of hand conducted by Hasanbegovic, Mahmutovic and Beha (2013).

However, the research conducted by Hasanbegovic, Mahmutovic and Beha (2013) on 425 signs reveal 41 different form of hand in total. This indicates that there are at least another 14 different shapes, which are given names by the authors in accordance with needs, necessary linguistic requirements and their own associations. Authors also mention certain signs in which these forms appear and recognize, so they can be distinguished.

\footnotetext{
${ }^{1}$ Correspodence to:

Esad H. Mahmutović, Center for Education and Rehabilitation of hearing and speech, Tuzla

Doboj Istok, B\&H

Phone: +387 61290780

E-mail: esad25@yahoo.com
} 
These authors state that: "The first description of linguistic units of signs in sign language, in the former Yugoslav regions, was given by Zimmerman in 1986, where he identified 27 forms of hand, and other types of units that he did not systemati-cally develop (see Appendix $)^{2}$. This description or representation has to this date been present in Bosnia and Herzegovina's educational and rehabilitation literature and applicable in theory and practice."

However, the research conducted by Hasanbegovic, Mahmutovic and Beha (2013) on 425 signs reveal 41 different form of hand in total. This indicates that there are at least another 14 different shapes, which are given names by the authors in accordance with needs, necessary linguistic requirements and their own associations. Authors also mention certain signs in which these forms appear and recognize, so they can be distinguished: Hand small $O$ : a pill, a day, better, a round button; Triple clip: BMW car; Collected fingers 3: experience, why; Hand flash: to throw, flowers, spring, to smell; Crooked fingers: camera, to escape; Spread crooked fingers: stingy, nervous; Big beak $U$ : inside, archives, soft, wet; Small beak U: small, blueberries; Small claw: Vienna; Hand E: euro, email, error, to hope; Middle $O$ : street, quickly, when, Africa, to reject; Hand marble: a detail, a whatnot, a marble, grain; Hand 4 spread: Croatia, hedgehog, crossword puz-zles, fan; Middle $C$ : headache, doctor, sore throat, Greece.

Aim: To visualize the newly discovered forms of hand, presented in study Hasanbegovic, Mahmutovic and Beha (2013), in order to ensure their adequate practical application in everyday communication of the deaf, various studies of sign language and future scientific analysis.

\section{METHODS}

The material of testing and determining the shape of hand was consisted of 425 video recordings, photographs and the drawings of sign SL in B\&H. The presence of the newly discovered shapes of the hand was found by the method of content analysis. Expert team of professionals participated in the analysis (surdoaudiologist, certificated interpreter - sign language translator and author of the dictionary). The results are presented with illustrations of the shape of hand and photographs of the signs SL in B\&H in which the shape of hand is represented.

\section{RESULTS}

In order to accurately recognize the newly discovered shapes of hand which are determined by the study Hasanbegovic, Mahmutovic and Beha (2013), and for their further use in scientific and professional activities, they are represented through illustrations (Illustrations 1-14), and for confirmation of the obtained results, for every shape of hand there is one sign from SL in B\&H shown via photograph (Photographs 1-14).

\section{Newly discovered shapes of hand and signs SL in B\&H in which they are represented}

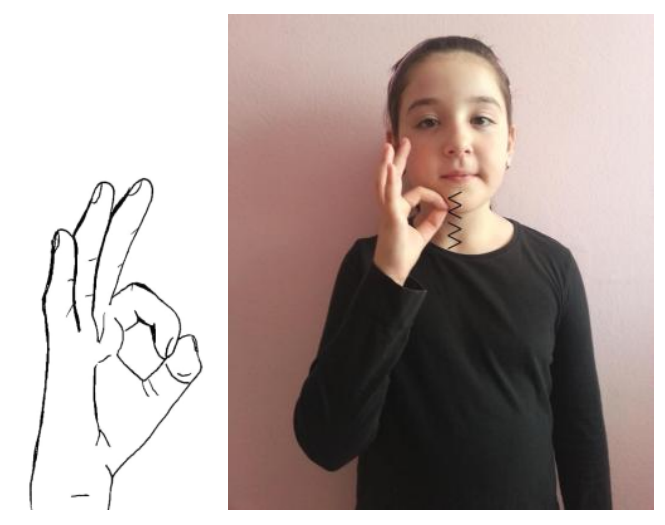

Illustration 1. Hand small O; Photo 1. Day

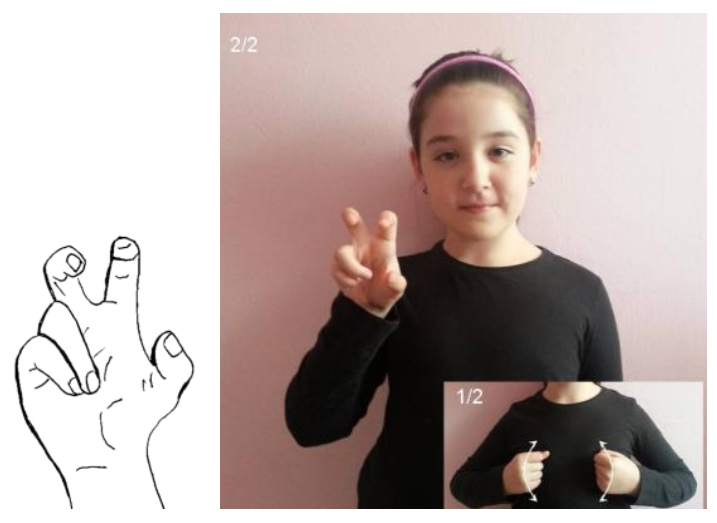

Illustration 2. Triple clip; Photo 2. BMW car

${ }^{2}$ Forms of hand in Appendix taken from „Do you speak sign? SUGOSG BIH (2005; 2007). 


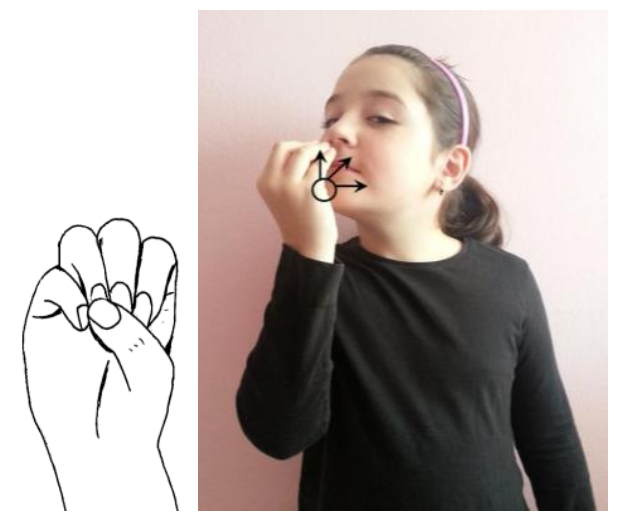

Illustration 3. Hand flash; Photo 3. Flowers

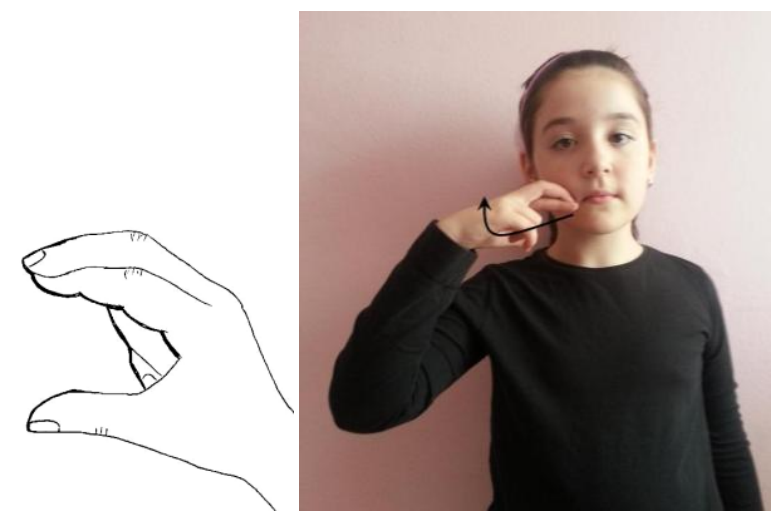

Illustration 5. Hand E; Photo 5. Euro

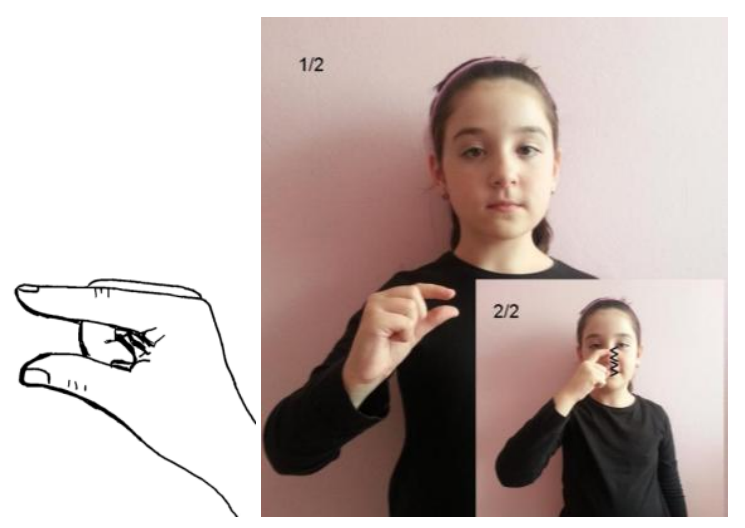

Illustration 7. Small beak U;Photo 7. Blueberries
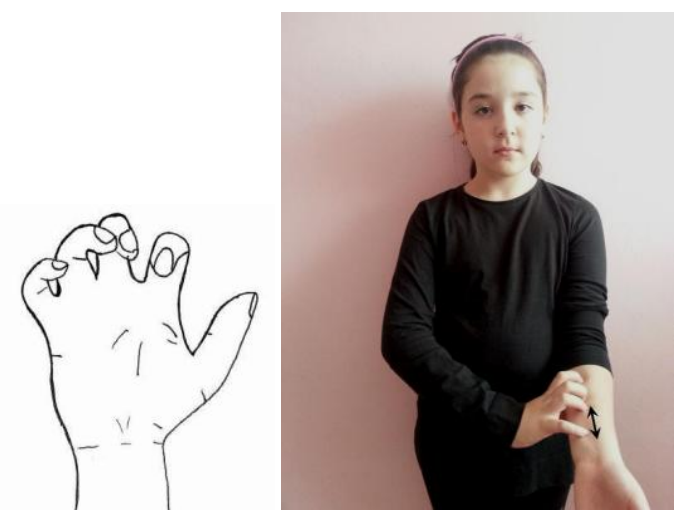

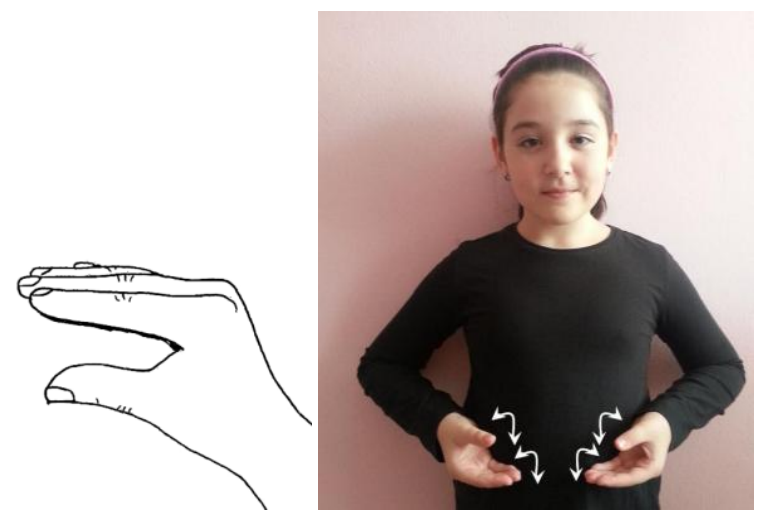

Illustration 4. Big beak U; Photo 4. Soft
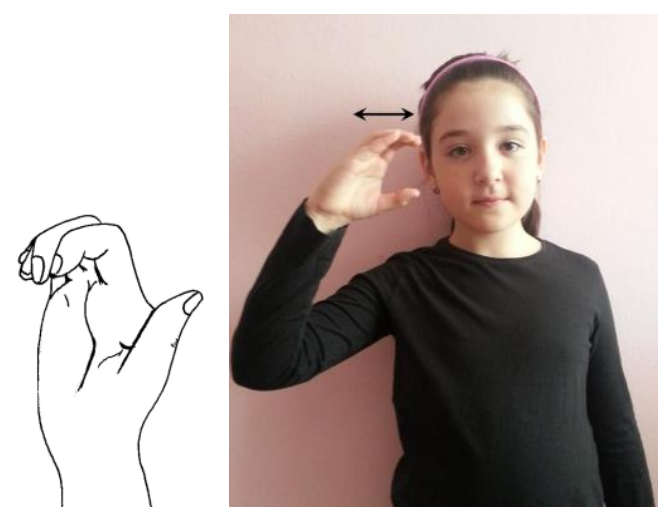

Illustration 6. Crooked fingers; Photo.6. Camera

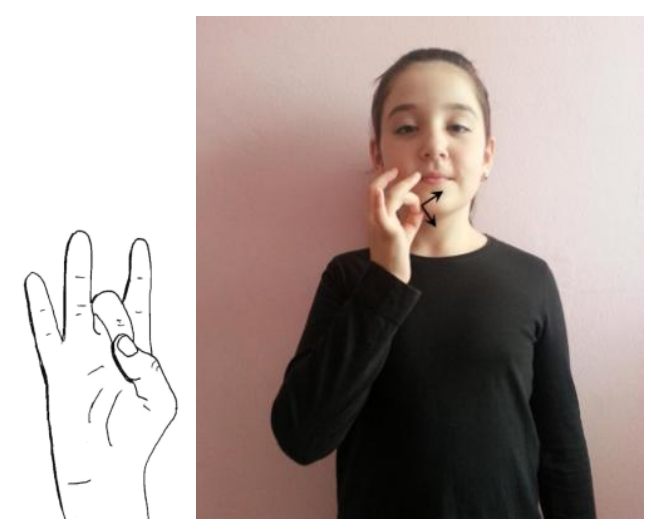

Illustration 8. Middle O;Photo 8. When?

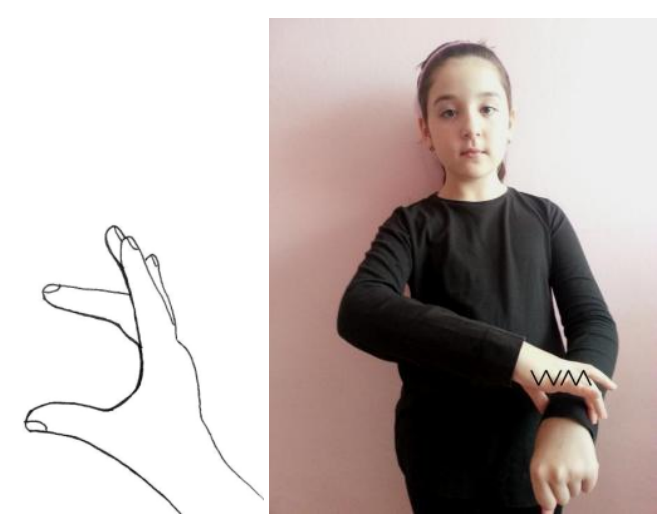

Illustration 9. Spread crooked fingers; Photo 9. Nervous Illustration 10. Middle C; Photo 10. Doctor 


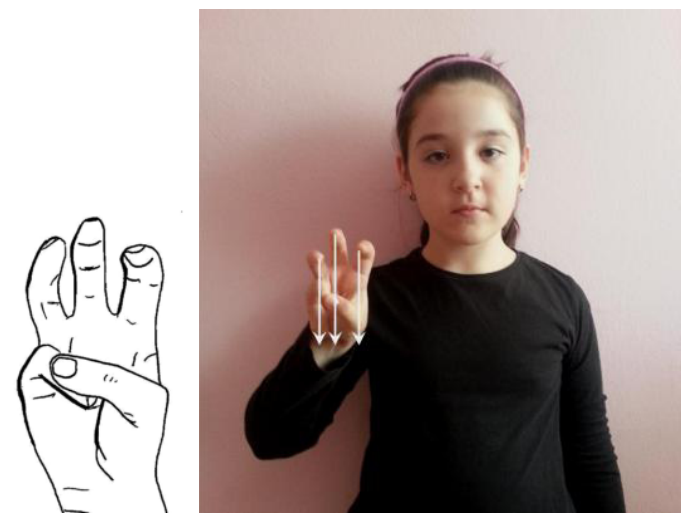

Illustration 11. Small claw; Photo 11.Vienna

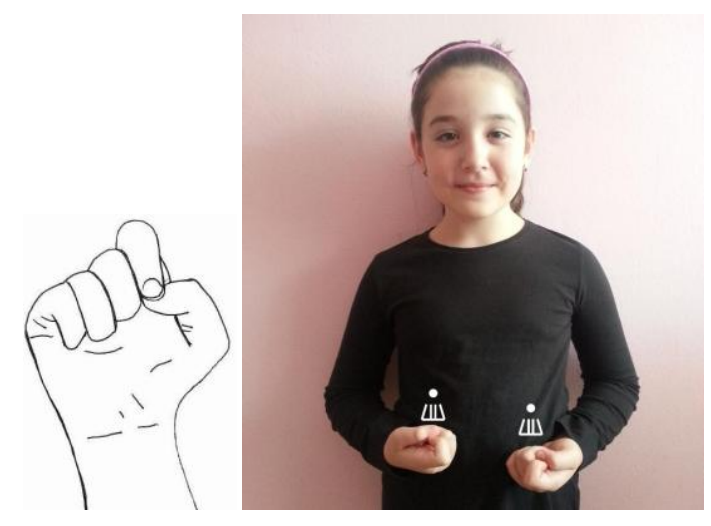

Illustration 13. Hand marble; Photo 13. A whatnot
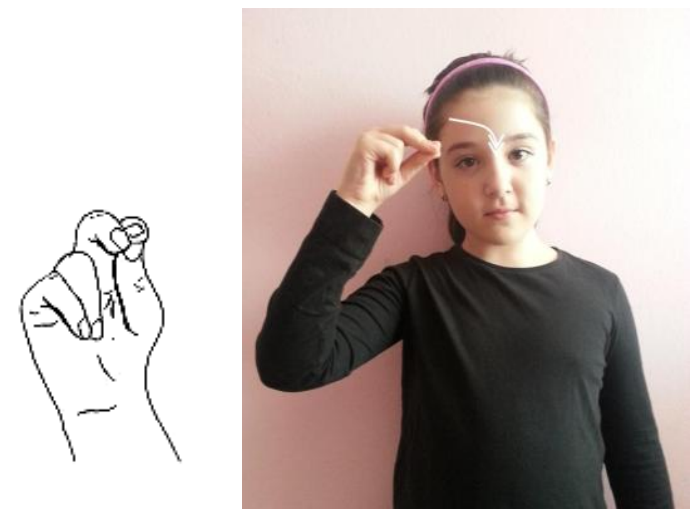

Illustration 12. Collected fingers 3; Photo 12. Experience

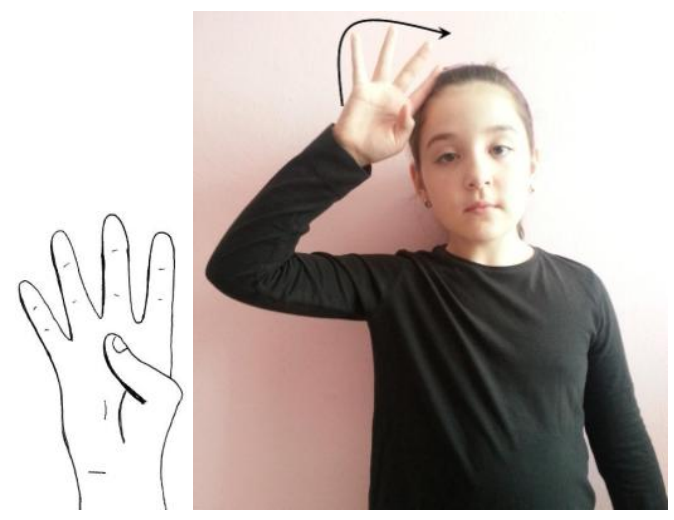

Illustration 14. Hand 4 spread; Photo 14. Hedgehog

\section{CONCLUSION}

The sign language of the deaf in $\mathrm{B} \& \mathrm{H}$ is uniform, insufficiently researched language system. This one, and the future linguistic studies, besides discovering the new shapes of hand, would significantly contribute to determination of the legality of complete linguistic structure, for the purpose of its use and standardization.

\section{REFERENCES}

Hasanbegović, H. (2004). Manual alphabet as an aid in understanding the language of deaf. Defektologija, 12, 89-92 .

Hasanbegovic, H. (2006). Rehabilitation programs in language development of the deaf. Doctoral dissertation. Univerzity of Tuzli. Faculty of Education and Rehabilitation.

Hasanbegovic, H. (2011). Bilingual glossary. Tuzla: OFF-SET. Hasanbegović H. (2012). Letter transformation at linguistic understanding of deaf people, US-China Foreign Language, 10 (4), 1061-1066.

Hasanbegovic, H., Mahmutovic, H.E., Beha, A. (2013). Forms of Hand in Sign Language in B\&H. HUMAN, 3 (2), 25-28 . Kasumovic, A., Hasanbegovic, H. (2002). Dictionary for the deaf. Tuzla: JU Public and University Library "Derviš Sušić" Tuzla.

Kasumovic, A., Hasanbegovic, H. (2005). Programmed alphabet as a support for language development of the deaf. Zbornik radova. 31(6). 115-119. Univerzity of Tuzli: Faculty of Philosophy.

Kurtagic, I. (2005) Difficulties and problems in communication of hard of hearing children with their parents in Bosnia and Herzegovina. Mostovi, 18/19. 22-25.

Mahmutovic, E. (2008). Theoretical and practical foundations for the formation of Bosnian sign language. Master thesis. Univerzity of Tuzli: Faculty of Education and Rehabilitation.

Salkic, N., (2008). The deaf between oralism and sign language. Master thesis. Univerzity of Tuzli: Faculty of Education and Rehabilitation.

SUGOSG B\&H. (2005). Do you speak sign?. Sarajevo: SUGOSIG B\&H: Centar za tumače znakovnog jezika

SUGOSG B\&H. (2007). Do you speak sign?. Sarajevo: SUGOSIG B\&H: Centar za tumače znakovnog jezika.

Zimmerman, A. (1986). An introductory seminar on communication with hearing impaired persons. Zagreb: Savez osoba oštećena sluha grada Zagreba. 


\section{APPENDIX 1}

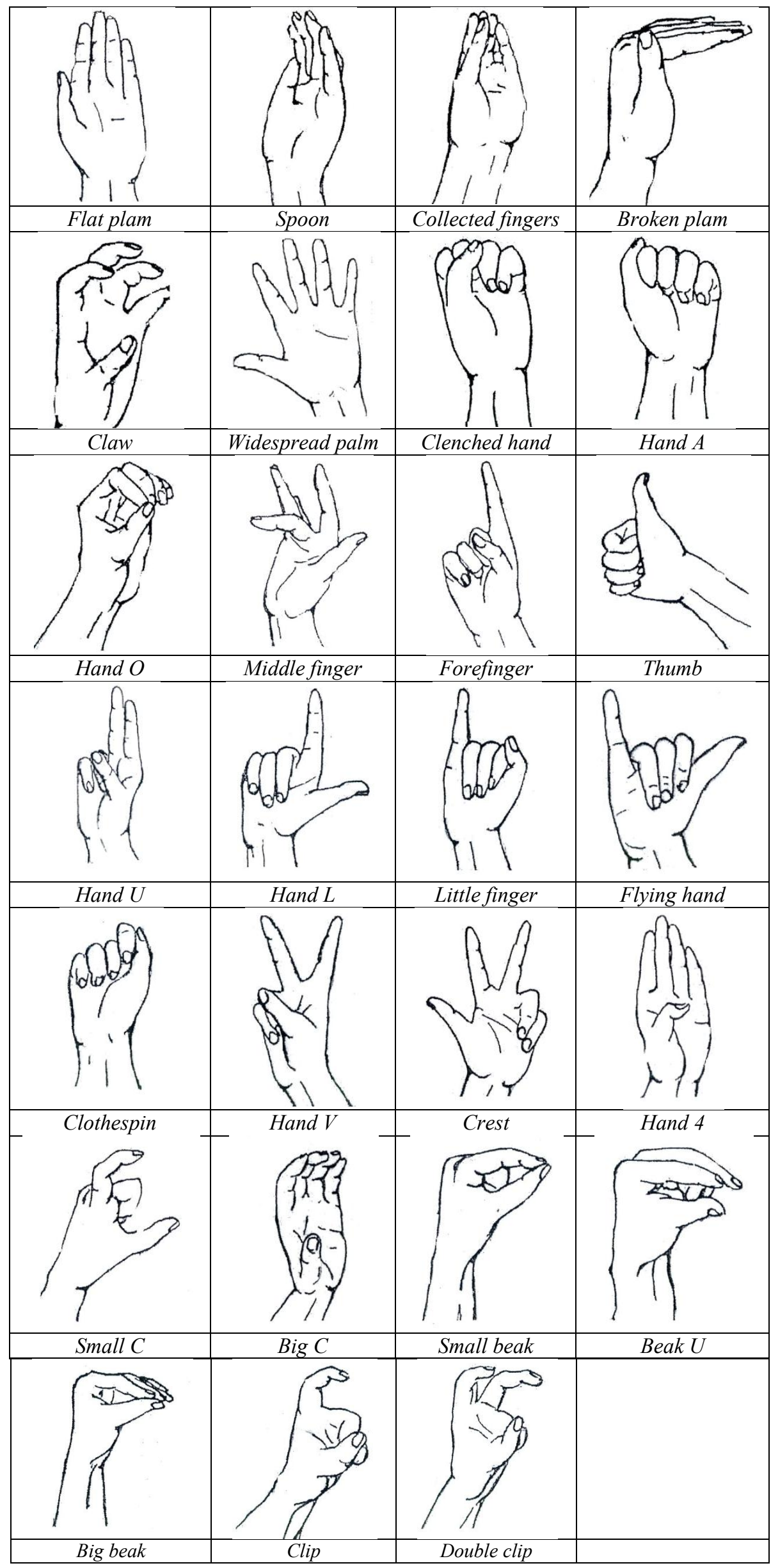

